\title{
Improving Power Quality with the Use of a New Method of Serial Active Power Filter (SAPF) Control
}

\author{
Roman Hrbac ${ }^{1}$, Tomas Mlcak ${ }^{1}$, Vaclav Kolar ${ }^{1}$ \\ ${ }^{I}$ Department of Electrical Engineering and Computer Science, VSB-Technical University of Ostrava, \\ 17. listopadu 15, Ostrava, Czech Republic \\ roman.hrbac@vsb.cz
}

\begin{abstract}
The quality of electric energy has currently become a widely discussed issue. The operation of appliances with nonlinear power consumption and with harmonic distorted current leads to voltage drops on network impedance, which in turn leads to power voltage distortion. To transform the distorted network voltage into harmonic voltage and thus improve the quality of electric energy, it is possible to use serial active power filters. SAPF can also be used as line conditioners. These devices are able to regulate supply voltage at the ends of a distribution grid, so that it meets the relevant standards. Line conditioners are also used in the increasingly widespread off grid systems. This paper deals with serial active power filter control. A new control method, called "comparative method", is presented. The efficiency of this method is demonstrated by measurement results, and compared with standard methods of active power filter control, such as the Butterworth filter method, or the Fast Fourier Transform based method.
\end{abstract}

Index Terms-Active filters, power control, power quality, converters, power harmonic filters.

\section{INTRODUCTION}

Nowadays, more and more appliances are characterised by non-linear consumption. This non-linear load is created by consumer electronics (switched power supplies) as well as industrial plants (frequency converters). These non-linear loads cause supply voltage distortion in distribution grids, which is due to grid impedance.

If power network distortion is so large that it does not meet the appropriate standards, it is necessary to use a suitable device to eliminate the distortion. Using a serial active power filter (SAPF) is a very convenient solution, which helps limit voltage distortion and thus ensure the quality of the power network.

SAPF may be used in extensive distribution grids, because voltage at their distant ends is altered and it may no longer correspond with the standards. In these cases, the costs of building a higher power rating distribution grid are much higher than SAPF based solutions, i.e. line conditioners. These devices work as supply voltage stabilisers in public distribution networks, operating within a wide range of input voltage. Line conditioners are also characterised by an

Manuscript received 11 January, 2016; accepted 8 October, 2016. This paper has been supported by project TACR: TH01020426. independent stabilising effect of individual output phases, a rapid effect and the ability to compensate short-term voltage drops [1].

In remote parts of the distribution grid, it is possible to use SAPF combined with a photovoltaic power plant. Such devices can both regulate and supply electrical energy [2]. Another area in which they can be used is off grids, parts of the ever more popular renewable energy systems [3]. SAPF can be used to stabilise the whole off grid system and to eliminate harmonics.

Harmonics occur very often, due to the character of the connected non-linear power supplies and loads [4].

Modified SAPF devices can first accumulate part of the energy in the network, and then cover even major network outages [5].

Currently, the methods which are most frequently used in SAPF control are also used for shunt power active filters [6]-[9]. Two commonly used methods were selected, namely the one based on the Butterworth filter with successive $4^{\text {th }}$ order approximation, and fast Fourier transform method. These methods were compared with the newly developed comparative method. Of course, there are also other options, e.g. the wavelet transform method [10], which is based on extracting the fundamental current component in order to build a low pass filter, or fuzzy logic control based solutions [11], [12].

If current harmonics caused by a non-linear load need to be removed, a combination of serial and shunt active power filters can be used. These are called hybrid filters [13]-[16].

Many publications in the field of control methods for active power filters are listed in [17], [18].

\section{BASIC FEATURES OF THE SERIAL ACtIVE FILTER}

Active filtration is based on the following principle. An additional controlled source $u_{\mathrm{C}}-$ a serial (voltage) active power filter - is serially connected to the power network. The sum of network voltage $u_{\mathrm{S}}$ and filter voltage $u_{\mathrm{C}}$ equals appliance voltage $u_{\mathrm{L}}$. Serial active power filters are used for adjusting power network voltage, in the direction from the supply side toward the appliance.

Serial active filters can be used [19], [20]:

- to compensate voltage drops on power supply 
impedance,

- to symmetrise and regulate power supply voltage,

- to filter voltage harmonics on appliance terminals,

- to supply energy in cases of $u_{\mathrm{s}}$, power outage, if the

filter is supplied from an independent source,

- to regulate phase shifts.

\section{Methods of Serial Active Power Filter Control IN A SIGNAL PROCESSOR}

This part of the paper deals with the discretisation of mathematical apparatus for different control methods. The word "discretisation" means the transformation of a continuous system described by differential equations, into a discrete system, expressed by recurrence relations. These recurrence relations are solved either by differential calculus methods, or using functional transformations of sequences. These transformations represent an apparatus equivalent to e.g. the Laplace transform, which is used in continuous system analysis. The most widely used functional transformation of sequences in discrete system theory is the $\mathrm{Z}$ transform. In cases when, under certain circumstances, signals may be considered periodical, they are described with the use of a finite discrete Fourier transform. The following is an analysis of all three control methods, implemented in a signal processor.

Three control methods have been implemented. The first one is based on the use of the low-pass frequency filter in a fourth order Butterworth filter (BF). The second method is based on the Fourier transform (FT). The third method is the comparative method (CM), which is based on the comparative of standardised sinusoidal waveforms.

\section{A. Butterworth Filter Based Control Method}

The design used in the signal processor was based on the IIR digital filter structure. We are going to use the fourthorder Butterworth approximation analogue prototype, whose transfer function is described in (1)

$$
\begin{gathered}
H(p)= \\
=\frac{1}{p^{4}+2,613126 \times p^{3}+3,414213 \times p^{2}+2,613126 \times p+1} .
\end{gathered}
$$

The transfer function of a standardised low pass filter is transformed into the low pass filter with a band pass cut-off frequency. The conversion relationship of the bilinear transformation is expressed by (2)

$$
p=\frac{2}{T} \times \frac{z-1}{z+1}
$$

After bilinear transformation and certain modification, the discrete form of the transmission equation is obtained (3)

$$
H(z)=\frac{c_{4}+c_{3} \times z^{-1}+c_{2} \times z^{-2}+c_{1} \times z^{-3}+c_{0} \times z^{-4}}{d_{4}+d_{3} \times z^{-1}+d_{2} \times z^{-2}+d_{1} \times z^{-3}+d_{0} \times z^{-4}} .
$$

Input-output relationships are described by the transmission function (1). Constants, which are obtained by coefficient calculation, as well as memory members in delay branches, form the complete mathematical apparatus, making it possible to calculate $y[n]$ values for each calculation step. This function is then implemented into the SAPF control algorithm, in the TMS320F2812 microprocessor.

\section{B. Fast Fourier Transform Based Control Method}

Fast Fourier Transform (FFT) algorithm is a highly effective way of discrete Fourier transformation (DFT). It is based on dividing final signal into shorter length signals, followed by DFT calculation and re-uniting the signals. This algorithm works faster when the number of samples is a power of 2. This method makes it possible to significantly reduce the number of arithmetic operations, especially for large sample sets.

The principle of the use of the FFT algorithm can be demonstrated on a simple example of a 4-point DFT. Relationship (4) shows DFT on four samples

$$
X(k)=\sum_{n=0}^{3} x(n) \times \exp \left(-\mathrm{j} \times \frac{2 \pi}{4} \times k \times n\right),
$$

where $k$ is $0,1,2,3$.

Numbers for $n$ and $k$ are put in the equation, and the equation in (4) is written for its individual components, thus obtaining four different equations. After simplifying and organising these relationships, we find out that the same operation is repeated four times in this algorithm and calculation signals cross. This operation is called "butterfly". The following FFT algorithm calculation is based on repeated butterfly calculations for different input data. Detailed description of this algorithm can be found in [8].

Therefore, if the individual amplitudes and phases of the corresponding harmonics with given frequencies are known, instantaneous voltages values of the given harmonics can be calculated according to (5)

$$
u_{\mathrm{C} k}=U_{\mathrm{C} k} \times \sin \left(k \times\left(\omega \times t+\phi_{k}\right)\right) \text {. }
$$

These voltages are then added according to (6), and the result is the control signal for PWM inverter.

$$
u_{\mathrm{C}}=\sum_{k=2}^{21} u_{\mathrm{C} k}
$$

\section{Comparative Method Based Control}

To be able to implement the comparative method, it is necessary to know the ideal harmonic sinusoidal waveform. In a signal processor, this problem is solved in the form of a table. The processor contains 4096 sine function values, which are gradually selected, according to the required angle, determined from the phase-locked loop board. Sine function is then calculated according to (7)

$$
u_{\mathrm{S}}{ }^{\prime}=U_{\mathrm{S} \max } \times \sin (\omega \times t+\phi) \text {. }
$$

The resulting control voltage is then calculated according to (8)

$$
u_{\mathrm{C}}=u_{\mathrm{S}}-u_{\mathrm{S}}^{\prime}
$$




\section{GENERAL DESCRIPTION OF THE CONTROL SYSTEM FOR SERIAL ACTIVE POWER FILTERS}

The whole control system is based on function blocks, which are formed by plug-in cards and operate on a common bus. The control system is created by a TMS320F2812 signal microprocessor, whose machine cycle is $6.67 \mathrm{~ns}$. The microprocessor forms part of the processor module card, which is in charge of data processing and implementing the required control algorithm. At the same time, this module also ensures communication with the superior PC with the use of RS 232 asynchronous serial line. Input data from sensors for the control system is provided by $\mathrm{A} / \mathrm{D}$ converter and phase-locked loop. Output switching pulse card and D/A converter card, are used to control the converter and for visualisation. A block diagram showing the connection of a measuring point, including the control system, can be found in Fig. 1.

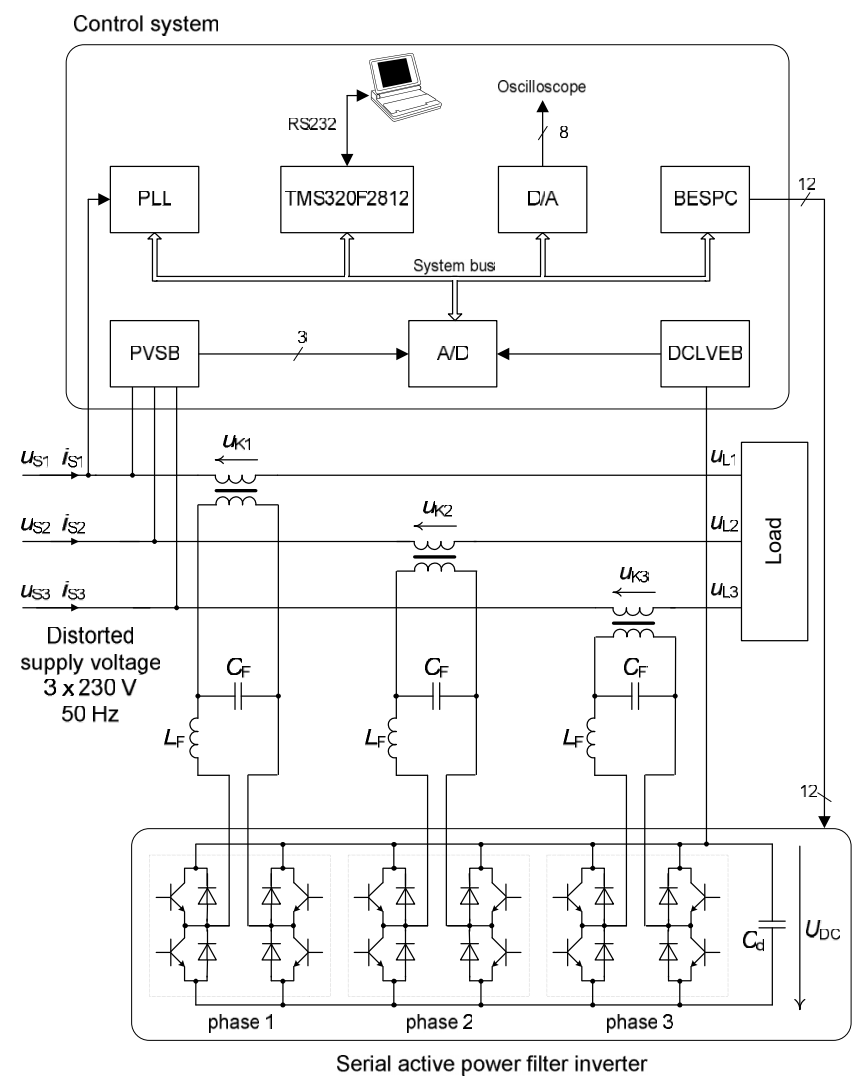

Fig. 1. Block diagram showing the connection of a measuring point, including the control system. TMS320F2812 - Digital Signal Processor by Texas Instrument Company; PLL - phase-locked loop (synchronisation); PVSB - phase voltage sensing block; DCLVEB - DC link voltage evaluation block; A/D - analog-to-digital converters; BESPC - block of emitting switching pulses for the converter; D/A - digital-to-analog converters.

\section{EXPERIMENTAL MEASUREMENTS}

These control methods have been verified by experimental measurements on a SAPF laboratory system. SAPF was tested for different supply voltage distortions and for different loads.

Figure 2 shows the diagram of the measuring stand. There is a regulating autotransformer located at the input. Its power rating is $7.5 \mathrm{kVA}$ and it is marked $T R A$. Delivery transformers are marked $T R_{1}, T R_{2}$ and $T R_{3}$. Figure 1 shows the diagram of the block converter. The measurement was performed for two types of loads, motor load and resistiveinductive load. The way in which the loads are connected is shown in Fig. 2.

System parameters:

1. Power network: $u_{\mathrm{S}}=3 \times 130 \mathrm{~V}$, regulating autotransformer $7.5 \mathrm{kVA}$.

2. Delivery transformers: Primary winding $300 \mathrm{~V}, 11.5 \mathrm{~A}$, Secondary winding $230 \mathrm{~V}, 15 \mathrm{~A}$.

3. Passive LC filters: $L_{\mathrm{F} 11}=L_{\mathrm{F} 12}=L_{\mathrm{F} 13}=1.2 \mathrm{mH}, L_{\mathrm{F} 21}=$ $L_{\mathrm{F} 22}=L_{\mathrm{F} 23}=2.8 \mathrm{mH}, C_{\mathrm{F} 1}=C_{\mathrm{F} 2}=C_{\mathrm{F} 3}=1.1 \mu \mathrm{F}$.

4. Load: AC motor $3 \times 230 \mathrm{~V} ; 2.2 \mathrm{~kW}$.

5. Resistive-inductive load: $L_{\mathrm{Z} 1}=L_{\mathrm{Z} 2}=L_{\mathrm{Z} 3}=4.5 \mathrm{mH}, R_{\mathrm{Z} 1}$ $=R_{\mathrm{Z} 2}=R_{\mathrm{Z} 3}=38 \Omega$.

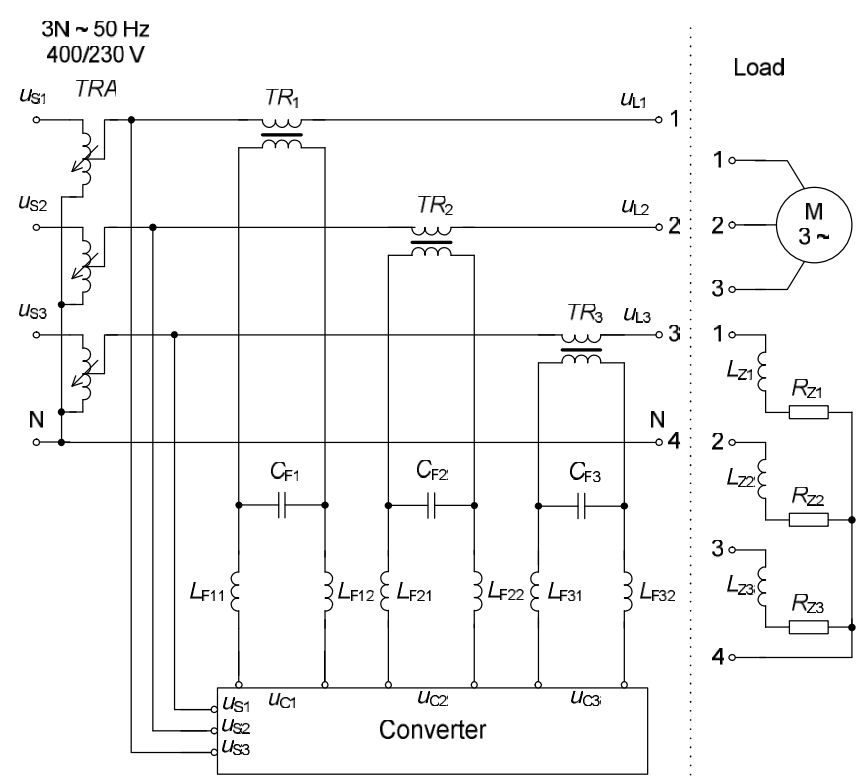

Fig. 2. Measuring stand diagram.

\section{A. Direct Connection to the Power Network}

In this measurement, SAPF was connected to the power network voltage with the use of an isolating transformer, as shown in Fig. 1. In the first case, the load was formed by a three-phase motor, whose power was $2.2 \mathrm{~kW}$. In the second case, the resistive-inductive load had the following parameters: $R=38 \Omega, L=4.5 \mathrm{mH}$. Network voltage $u_{\mathrm{S} 1}$ and compensated voltage $u_{\mathrm{L} 1}$ for the comparative method for resistive-inductive load is shown in Fig. 3.

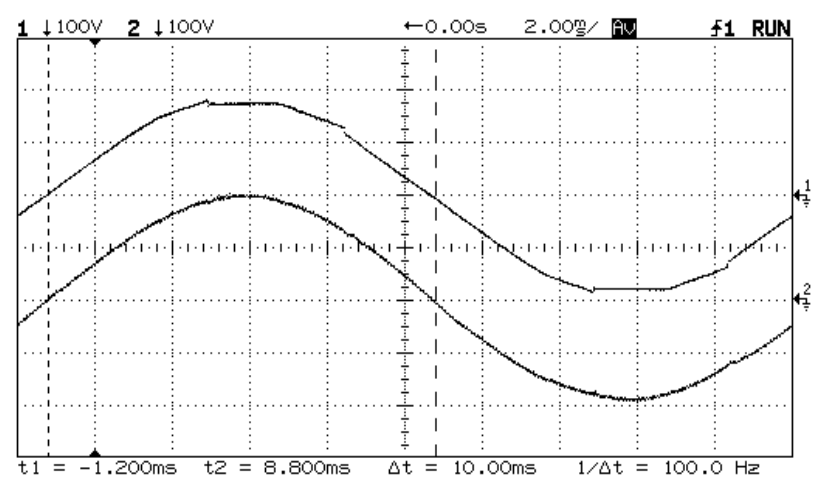

Fig. 3. Control using the comparative method with resistive-inductive load. Channel 1 - input voltage (power network voltage) $u_{\mathrm{s} 1}$, channel $2-$ output voltage filtered by SAPF $u_{\mathrm{L} 1}$.

Voltage waveforms for the other methods look similar. Total harmonic distortion values of compensated waveforms 
for all methods and both load types are shown in Table I. Total harmonic distortion of the network was $T H D_{\mathrm{U}}=4.42 \%$.

TABLE I. TOTAL HARMONIC DISTORTION VALUES OF COMPENSATED WAVEFORMS FOR ALL METHODS AND BOTH LOAD TYPES

\begin{tabular}{|c|c|c|}
\hline \multirow{2}{*}{ Method } & \multicolumn{2}{|c|}{$\boldsymbol{T H D}_{\boldsymbol{U}}(\mathbf{\%})$} \\
\hline & Motor load & Resistive-inductive load \\
\hline BF & 1.48 & 1.80 \\
\hline FT & 1.69 & 1.35 \\
\hline MK & 1.07 & 0.99 \\
\hline
\end{tabular}

\section{B. Voltage Distorted by a Three-Phase Rectifier}

In this measurement, inductors are serially connected to the inlet. After them, a three-phase six-pulse rectifier with resistive-capacitor load is connected in parallel. The inductors at the inlet behave like a long power line. The sixpulse rectifier generates the $5^{\text {th }}, 7^{\text {th }}, 11^{\text {th }}, 13^{\text {th }}$ etc. current harmonics. These current harmonics then cause voltage drops on the impedance of the inductor, create voltage distortion. This makes it possible to achieve a greater distortion of input supply voltage for the serial active power filter. Voltage waveforms may be seen in the following Figures.

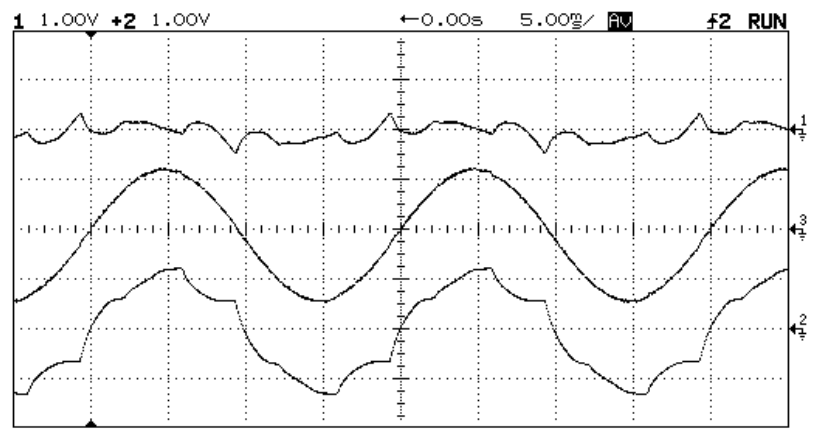

Fig. 4. Control using the comparative method with resistive-inductive load. Channel 1 - compensating voltage generated by the filter $u_{\mathrm{c} 1}$, channel 3 - output voltage filtered by SAPF $u$ L1, channel 2 - input voltage distorted by a three-phase rectifier $u$ si.

TABLE II. TOTAL HARMONIC DISTORTION VALUES FOR ALL METHODS AND BOTH LOAD TYPES (THREE-PHASE RECTIFIER).

\begin{tabular}{|c|c|c|}
\hline \multirow{2}{*}{ Method } & \multicolumn{2}{|c|}{$\boldsymbol{T H D _ { U } ( \mathbf { \% } )}$} \\
\cline { 2 - 3 } & Motor load & Resistive-inductive load \\
\hline BF & 2.74 & 2.64 \\
\hline FT & 2.26 & 2.23 \\
\hline MK & 1.99 & 1.81 \\
\hline
\end{tabular}

Figure 4 shows phase waveforms of deformed network voltage through a three-phase rectifier $u_{\mathrm{S} 1}$, voltage generated by filter $u_{\mathrm{C} 1}$ and compensated voltage $u_{\mathrm{L} 1}$ for the comparative method and resistive-inductive load. Table II contains total harmonic distortion values for all methods and both load types. Total harmonic distortion of voltage deformed by a three-phase rectifier is $T H D_{\mathrm{U}}=9.92 \%$.

\section{Voltage Distorted by a Single-Phase Rectifier}

In this measurement, there are again inductors serially connected at the inlet. After them, a single-phase two-pulse rectifier with resistive-capacitive load is connected in the second phase. The two-pulse rectifier generates $3^{\text {th }}, 5^{\text {th }}, 7^{\text {th }}$, $9^{\text {th }}, 11^{\text {th }}, 13^{\text {th }}$ etc. current harmonics. This makes it possible to achieve a greater distortion of input supply voltage, where total harmonic distortion is almost $15 \%$.

Figure 5-Fig. 7 show waveforms for resistive-inductive load. Figure 8 shows phase waveforms of input voltages $u_{\mathrm{S} 1}$, $u_{\mathrm{S} 2}, u_{\mathrm{S} 3}$ with single-phase rectifier deformation in the second phase. Figure 9 shows the waveforms of compensated voltage $u_{\mathrm{L} 1}, u_{\mathrm{L} 2}, u_{\mathrm{L} 3}$ for the comparative method and motor load. Table III shows total harmonic distortion values for all methods and both load types. Total harmonic distortion of voltage distorted by a single-phase rectifier is $T H D_{\mathrm{U}}=14.71 \%$.

TABLE III. TOTAL HARMONIC DISTORTION VALUES FOR ALL METHODS AND BOTH LOAD TYPES (SINGLE-PHASE RECTIFIER).

METHODS AND BOTH LOAD TYPES (SINGLE-PHASE RECTIFIER).
\begin{tabular}{|c|c|c|}
\hline \multirow{2}{*}{ Method } & \multicolumn{2}{|c|}{$\boldsymbol{T H D}_{\mathbf{U}}(\%)$} \\
\cline { 2 - 3 } & Motor load & Resistive-inductive load \\
\hline BF & 4.41 & 3.54 \\
\hline FT & 4.05 & 3.89 \\
\hline MK & 3.33 & 2.86 \\
\hline
\end{tabular}

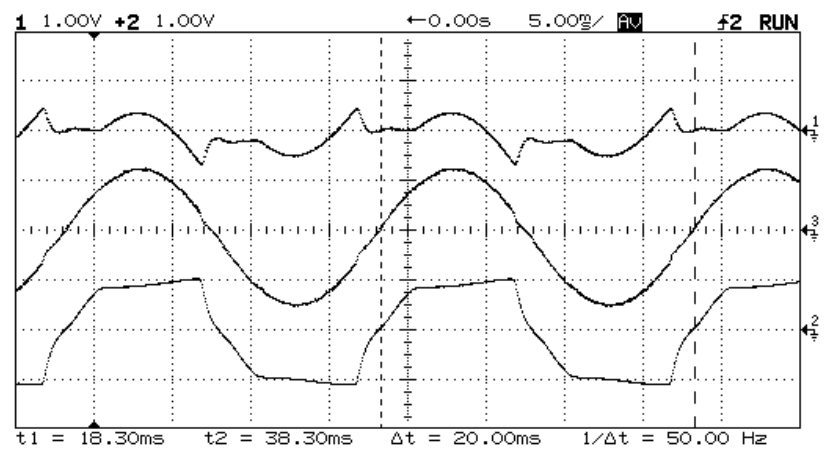

Fig. 5. Control using the BF control method with resistive-inductive load Channel 1 - compensating voltage generated by the filter $u_{\mathrm{c} 1}$, channel 3 output voltage filtered by SAPF $u_{\mathrm{L} 1}$, channel 2 - input voltage distorted by a single-phase rectifier $u_{\mathrm{S} 1}$.

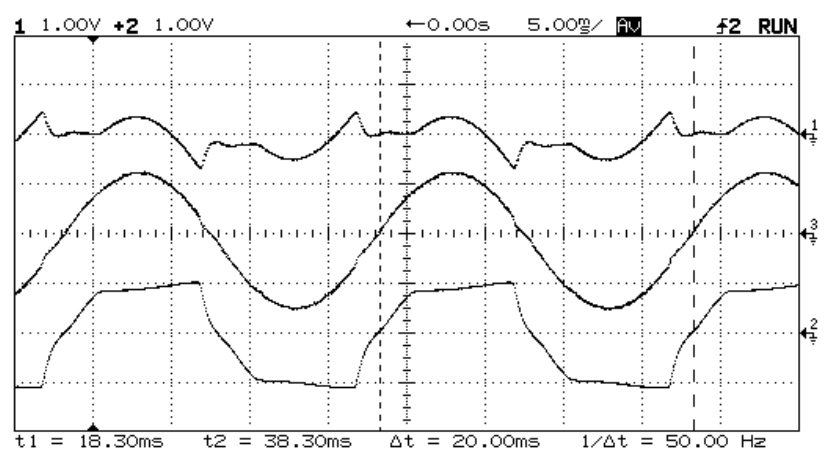

Fig. 6. Control using the FFT control method with resistive-inductive load. Channel 1 - compensating voltage generated by the filter $u_{\mathrm{c} 1}$, channel 3 output voltage filtered by SAPF $u_{\mathrm{L} 1}$, channel 2 - input voltage distorted by a single-phase rectifier $u_{\mathrm{S} 1}$.

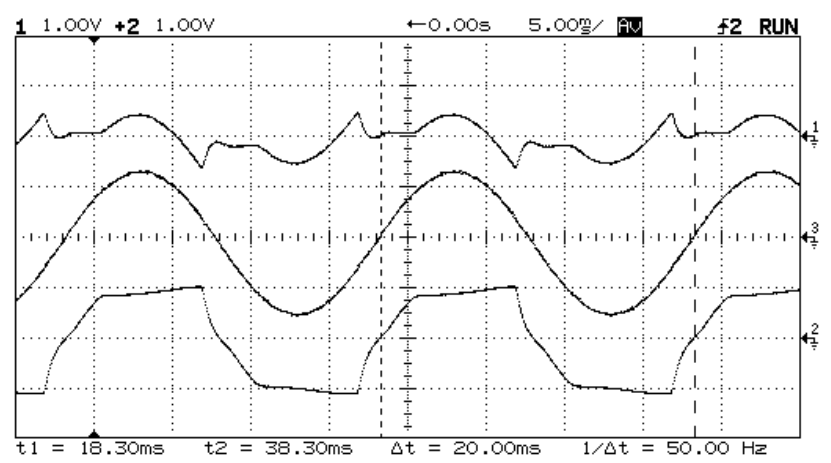

Fig. 7. Control using the comparative method with resistive-inductive load. Channel 1 - compensating voltage generated by the filter $u_{\mathrm{c} 1}$, channel 3 - output voltage filtered by SAPF $u$ L1, channel 2 - voltage distorted by a single-phase rectifier $u$ si. 


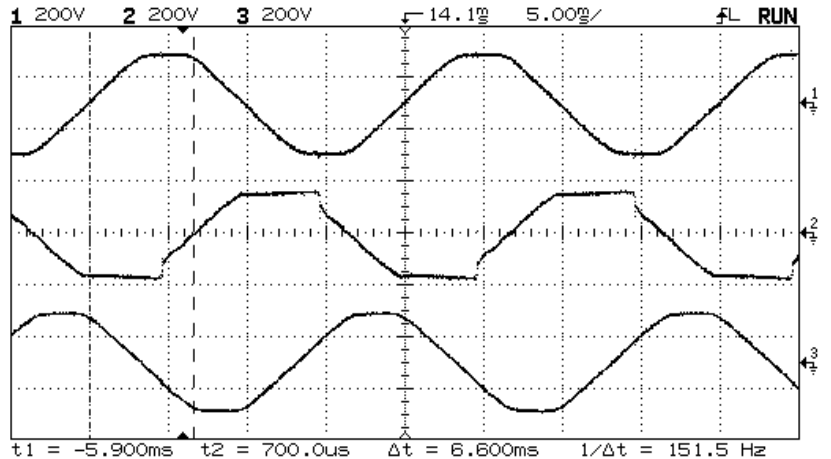

Fig. 8. Three-phase waveforms of input voltages, channel 1 - power network voltage $u \mathrm{~s}$, channel 2 - voltage distorted by a single-phase rectifier $u_{\mathrm{S} 2}$, channel 3 - power network voltage $u_{\mathrm{S} 3}$.

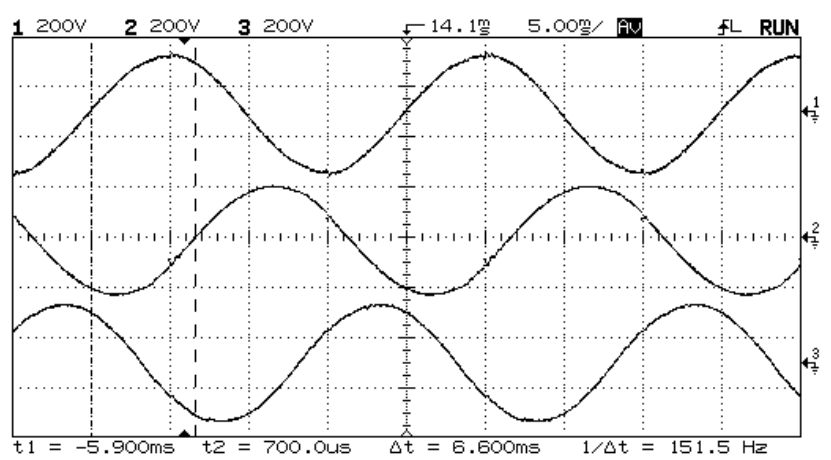

Fig. 9. Control using the comparative method with motor load. Channel 1, 2 and 3 - voltage behind SAPF $u_{\mathrm{L} 1}, u_{\mathrm{L} 2}$ and $u_{\mathrm{L} 3}$.

\section{Connection to an AFE Unit}

In this measurement, a Siemens AFE (Active Front End) unit was used as the load. This AFE unit is said to work as an intelligent regenerative rectifier for SIMOVERT MASTERDRIVES converters. As stated by the manufacturer, this unit ensures sinusoidal current consumption, which means that it does not load the network with harmonic currents. To achieve this, it is necessary to ensure ideally sinusoidal supply voltage, which is usually not found in the low-voltage power network. Otherwise, the unit generates current harmonics with such amplitudes and phases, which cause voltage distortion suppression. When connecting this unit to distorted supply voltage, nonharmonic current is consumed, but the overall situation in the network should improve.

Figure 10 shows voltage and current waveforms when connecting the AFE unit directly to the network.

It is obvious that the current waveform is highly nonharmonic. RMS current value is $5.68 \mathrm{~A}$, and it is $228.4 \mathrm{~V}$ for voltage. Total harmonic distortion is $T H D_{U}=4.35 \%$ for voltage and $T H D_{I}=24.01 \%$ for current.

Figure 11 shows voltage and current waveforms when connecting an AFE unit after the serial active power filter. Current waveform tries to copy power voltage and thanks to the harmonic power voltage from SAPF, it looks much more like a sinusoidal waveform. RMS values are $8.16 \mathrm{~A}$ for current and $232.6 \mathrm{~V}$ for voltage. Total harmonic distortion is $T H D_{\mathrm{U}}=3.25 \%$ for voltage and $T H D_{\mathrm{I}}=8.14 \%$ for current.

BK 550 power quality analyser by ELCOM, Inc. was used to measure $P_{2} \mathrm{p}$ and $P_{1}$ power for individual currents. A system with an AFE unit was used as the load. This made it possible to achieve a load of $10 \mathrm{~A}$. Input power from the distribution network (P1) and output power (P2) were measured. The $\mathrm{P} 1 / \mathrm{P} 2$ ratio is called total SAPF efficiency. The graph in Fig. 12 shows the efficiency of a serial active power filter for different $I_{\mathrm{L} \text { RMS }}$ current values.

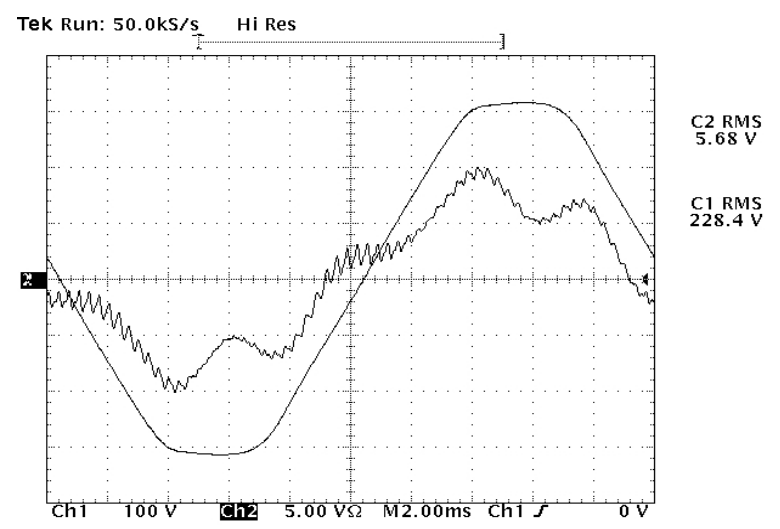

Fig. 10. Voltage and current waveforms when connecting an AFE unit directly to the network.

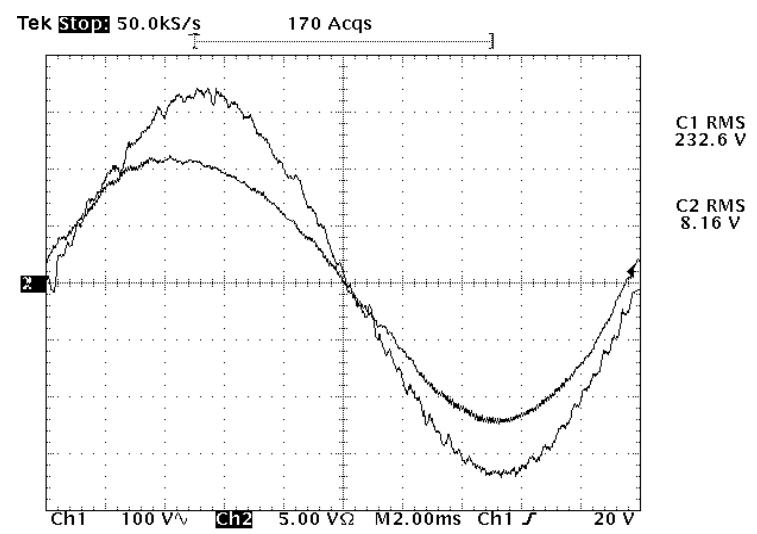

Fig. 11. Voltage and current waveforms when connecting an AFE unit behind the SAPF.

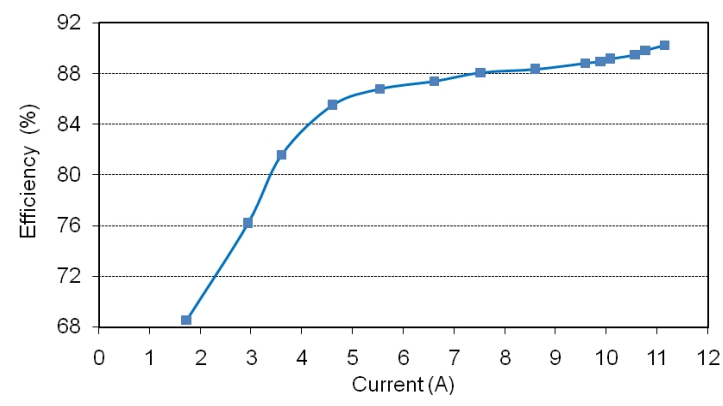

Fig. 12. Total SAPF efficiency for different $I_{\mathrm{L}}$ RMS current values (A).

The efficiency waveform shows that the higher the output SAPF current value is, the higher the efficiency can be. Because of the load used, it was impossible to test the system with nominal loading. We assume maximum SAPF efficiency is approximately $95 \%$. Further measurements will be performed to verify this.

\section{CONCLUSIONS}

The analysis of control methods presented in this paper was performed on a serial active power filter prototype. Three control methods were tested on an actual SAPF model: the Butterworth filter method with successive $4^{\text {th }}$ order transformation, Fast Fourier transform method and the newly developed comparative method.

This paper presents the comparative method, a novel SAPF control solution developed by the authors. This 
method has been tested on a SAPF prototype, and it has been found to be fully functional. Experimental measurements have shown that this is the best method for SAPF control. It also has the best response to dynamic changes within the system. This solution was developed and tested by the authors, and has no relation to any known solution. Research was done to investigate existing SAPF control methods, and no similar solution was found.

The authors are currently working on the modification of the SAPF control solution above described with the use of the comparative method. This modification consists of evaluating actual conditions in the network and modifying output voltage within the permitted limits. Deviation from the nominal voltage as stated by the relevant standard is $230 \mathrm{VAC} \pm 10 \%$. In this case, the loading of power elements of the filter decreases, making it possible to use the SAPF power range more effectively. This SAPF control method would make the whole system more efficient.

\section{REFERENCES}

[1] S. Ganguly, "Unified power quality conditioner allocation for reactive power compensation of radial distribution networks", IET Generation, Transmission and Distribution, vol. 8, no. 8, pp. 14181429 , 2014. [Online]. Available: http://dx.doi.org/10.1049/ietgtd.2013.0382

[2] S. Ganguly, "Design and simulation of a unified power quality conditioner fed by solar energy", International Journal of Hydrogen Energy, vol. 40, no. 44, pp. 15267-15277, 2015. [Online]. Available: http://dx.doi.org/10.1016/j.ijhydene.2015.02.077

[3] J. Stuchly, S. Misak, T. Vantuch, T. Burianek, "A power quality forecasting model as an integrate part of active demand side management using artificial intelligence technique - multilayer neural network with backpropagation learning algorithm", IEEE 15th Int. Conf. Environment and Electrical Engineering (IEEE EEEIC 2015), Rome, Italy, 2015, pp. 611-616. [Online]. Available: http://dx.doi.org/10.1109/EEEIC.2015.7165233

[4] S. Misak, J. Stuchly, J. Platos, P. Kromer, "A heuristic approach to active demand side management in off-grid systems operated in a smart-grid environment", Energy And Buildings, vol. 96, pp. 272284, 2015. [Online]. Available: http://dx.doi.org/10.1016/j.enbuild. 2015.03 .033

[5] S. Misak, J. Stuchly, J. Vramba, T. Vantuch, D. Seidl, “A novel approach to adaptive active relay protection system in single phase AC coupling Off-Grid systems", Electric Power Systems Research, vol. 131, pp. 159-167, 2016. [Online]. Available: http://dx.doi.org/ 10.1016/j.epsr.2015.10.015

[6] M. Habrych, G. Wisniewski, B. Miedzinski, J. Wosik, A. Kozlowski, "Possibility of load balancing in middle voltage network with the use of active power filter", Elektronika ir Elektrotechnika, vol. 21, no. 5, pp. 19-23, 2015. [Online]. Available: http://dx.doi.org/10.5755/ j01.eee.21.5.13319

[7] J. H. Yao, J. C. Liu, "The optimal design of parallel active power filter", 2nd Int. Conf. Intelligent Computation Technology and
Automation, Changsha, Peoples rep. China, 2009, vol. 3, pp. 103 106. [Online]. Available: http://dx.doi.org/10.1109/ICICTA.2009.493

[8] J. Wosik, A. Kozlowski, M. Habrych, M. Kalus, B. Miedzinski, "Study on performance of non-linear reactive power compensation by using active power filter under load conditions", Elektronika ir Elektrotechnika, vol. 22, pp. 19-23, 2016. [Online]. Available: http://dx.doi.org/10.5755/j01.eee.22.1.14098

[9] R. Hou, J. Wu, YC. Liu, D. G. Xu, "Generalized design of shunt active power filter with output LCL filter", Elektronika ir Elektrotechnika, vol. 20, no. 5, pp. 65-71, 2014, [Online]. Available: http://dx.doi.org/10.5755/j01.eee.20.5.3910

[10] S. Y. Kamble, S. N. Mate, M. M. Waware, "Online wavelet based control algorithm for shunt active power filter operation", IEEE Int Conf. On Control Applications (CCA 2013), 2013, pp. 1153-1158. [Online]. Available: https://doi.org/10.1109/CCA.2013.6662907

[11] B. K. Narukullapati, P. V. S. Sobhan, C. N. Narsimha Rao, A. Sriharibabu, "Modeling and simulation of shunt APF with hysterisis and fuzzy logic controller with and without faults", Journal of Theoretical and Applied Information Technology, vol. 64, no. 3, pp. 781-794, 2014.

[12] R. Belaidi, A. Haddouche, H. Guendouz, "Fuzzy logic controller based three-phase shunt active power filter for compensating harmonics and reactive power under unbalanced mains voltages", Energy Procedia, vol. 18, pp. 560-570, [Online]. Available: http://dx.doi.org/10.1016/j.egypro.2012.05.068

[13] F. Gong, X. Y. Xia, S. W. Luo, F. Zhou, "High-capacity hybrid active power filter for the power", Advances in Intelligent and Soft Computing, vol. 110, no. 1, pp. 95-100, 2011. [Online]. Available: https://doi.org/10.1007/978-3-642-25185-6_13

[14] L. Hong, H. Yan, Y. F. Xi, X. Chen, G. Z. Chen, "Design of DC-bus voltage controller for hybrid active power filter based on pole-zero placement", 20th IEEE Int. Symposium on Industrial Electronics (ISIE 2011), Gdansk, Poland, 2011. [Online]. Available: https://doi.org/10.1109/ISIE.2011.5984159

[15] O. G. Sokmen, S. A. Tekin, H. Ercan, M. Alci, "A Novel Design of Low-Voltage VDIBA and Filter Application", Elektronika ir Elektrotechnika, vol. 22, no. 6, pp. 51-56, 2016. [Online]. Available: http://dx.doi.org/10.5755/j01.eie.22.6.17224

[16] S. Biricik, O. C. Ozerdem, S. Redif, M. I. O. Kmail, "Performance improvement of active power filter under distorted and unbalanced grid voltage conditions", Elektronika ir Elektrotechnika, vol. 19, no. 1, pp. 35-39, 2013. [Online]. Available: http://dx.doi.org/ 10.5755/j01.eee.19.1.3247

[17] S. Zhang, D. Li, X. Wang, "Control techniques for active power filters", Int. Conf. Electrical and Control Engineering (ICECE), 2010, pp. 3493-3498, [Online]. Available: http://dx.doi.org/10.1109/ iCECE. 2010.850

[18] T. C. Green, J. H. Marks, "Control techniques for active power filters", IEE Proc. Electric Power Applications, vol. 152, no. 2, 2005, pp. 369-381. [Online]. Available: http://dx.doi.org/10.1049/ipepa:20040759

[19] N. F. Teixeira, J. G. O. Pinto, M. J. S. Freitas, J. L. Afonso, "New control algorithm for single-phase series active power filter", Electric Power Components And Systems, vol. 43, no. 15, pp. 1752-1760, 2015. [Online]. Available: http://dx.doi.org/10.1080/15325008. 2015.1051166

[20] R. Strzelecki, H. Supronowicz, Filtracja harmonicznych $w$ sieciach zasilajacych pradu przemiennego. Wydawnictwo Adam Marszalek: Torun, 1999. (in Polish). 